\begin{tabular}{|c|c|c|}
\hline & Int.J.Curr.Microbiol.App.Sci (2016) 5(11): 205-221 & \multirow{4}{*}{ 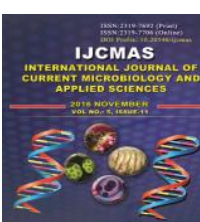 } \\
\hline & \multirow{4}{*}{$\begin{array}{l}\text { International Journal of Current Microbiology and Applied Sciences } \\
\text { ISSN: 2319-7706 Volume } 5 \text { Number } 11 \text { (2016) pp. 205-221 } \\
\text { Journal homepage: http://www.ijcmas.com }\end{array}$} & \\
\hline & & \\
\hline EXCELLENT & & \\
\hline PUBLISHERS & & www:jemas. com \\
\hline
\end{tabular}

Original Research Article

http://dx.doi.org/10.20546/ijcmas.2016.511.023

\title{
Preparation of Antibacterial Herbal Mouthwash against Oral Pathogens
}

\author{
J. Nasreen Banu* and V. Gayathri \\ Department of Microbiology, Ethiraj College for Women, Chennai- 600008, Tamil Nadu, India \\ *Corresponding author
}

\begin{tabular}{l} 
K e y w o r d s \\
Antibacterial, \\
Herbal Mouthwash, \\
Staphylococcus \\
aureus, Lactobacillus \\
bulgaricus, \\
Bacillus subtilis, \\
Streptococcus \\
pyogenes, \\
Escherchia coli. \\
\hline Article Info \\
\hline \\
Accepted: \\
12 October 2016 \\
Available Online: \\
10 November 2016 \\
\end{tabular}

\begin{abstract}
A B S T R A C T
Medicinal plants, plays vital role in curing diseases due to their antimicrobial and antifungal activity against human pathogens through decades. Herbal Mouthwashes are in high demand, because thy act on oral pathogens and relieve the pain instantly and are also less side effective. One of the most common infectious diseases encountered by many individuals are Dental carries and Periodontal diseases at different stages of their life time. Dental caries include the cavity formation, eruption of enamel, swollen gums, bleeding gums, formation of hollow black eruption on the surface of the teeth. In early days, Dental caries are high among Children and Adolescents, because they do not practice proper oral hygiene. To prepare Anti-bacterial Herbal Mouthwash from the aqueous extracts of 4 different leaves namely Azadirachta indica (Neem), Ocimum basilicum (Tulsi), Mentha longifolia (Mint), Punica granetum Linn (Pomegranate) and rhizomes of Curcuma longa (Turmeric) that acts against the oral pathogensStaphylococcus aureus, Streptococcus pyogenes, Lactobacillus bulgaricus, Bacillus subtilis and Escherchia coli and to check the Anti-microbial activity by using Agar well diffusion method. Punica granetum Linn(Pomegranate) shows sensitivity towards the Streptococcus pyogenes, Lactobacillus bulgaricus, Staphylococcus aureus, Bacillus subtilis and Escherchia coli. Azadirachta indica (Neem) shows sensitivity towards Staphylococcus aureus and Escherchia coli and shows resistance towards Streptococcus pyogenes, Lactobacillus bulgaricus and Bacillus subtilis. Ocimum baslicum (Tulsi) shows sensitivity towards Staphylococcus aureus, Bacillus subtilis and Escherchia coli and shows resistance towards Streptococcus pyogenes, Lactobacillus bulgaricus. Mentha longifolia (Mint) shows sensitivity towards Staphylococcus aureus, Lactobacillus bulgaricus and Escherchia coli and shows resistance towards Streptococcus pyogenes and Bacillus subtilis. Curcuma longa (Turmeric) shows sensitivity towards Lactobacillus bulgaricus, Staphylococcus aureus and Escherchia coli and shows resistance towards Streptococcus pyogenes, Bacillus subtilis. Hence this study proves that Punica granetum Linn(Pomegranate) shows effectiveness against all the 5 oral bacterias namely Streptococcus pyogenes, Lactobacillus bulgaricus, Staphylococcus aureus, Bacillus subtilis and Escherchia coli. Pomegranate leaves possess flavonoids which is used as an anti-oxidant in conditions of Xerotomia. Thereby, Pomegranate leaves can also be included in the preparation of Herbal mouthwashes.
\end{abstract}

\section{Introduction}

The importance of herbs are highly considered as effective in contrast to chemical products. Medicinal plants, plays vital role in curing diseases due to their antimicrobial and antifungal activity against human pathogens through decades. 
Herbal Mouthwashes are in high demand, because thy act on oral pathogens and relieve the pain instantly and are also less side-effective. Chemical mouthwashes have hydrogen peroxide and chlorhexidine as an immediate whitener, steriliser and pain reliever of teeth, but they tend to produce discoloration of teeth and may produce side effect, meanwhile they are cost effective. One of the most common infectious diseases encountered by many individuals are Dental carries and Periodontal diseases at different stages of their life time.

Periodontal diseases can lead to destruction of ligament, cementum, gingiva and alveolar bone. Plaque is the main etiological causes for the gingival inflammation. Thus the control of the plaque can be done by using instant herbal mouth wash. Mouth washes have the ability to deliver the therapatic ingredients and ingredients to access against the organism present on the surface of the mouth. Cholorhexidine is regarded as gold standard mouth wash but has a significant side effects, apart from staining the teeth after long term use, like contact dermatitis, $\operatorname{IgE}$ mediated hypersensitivity (Monica Lamba, 2015).

The role of junk foods in affecting the oral cavity of an individual is high and unavoidable. The foods like Candies, chocolates, jellies and jams have high sugar content the children and adolescents are usually prone to consume this kind of sugar products but, the sugar content possess insoluble glucan which gets attached to the enamel of the tooth resulting in the formation of cavity in tooth. The carbonated drinks is other important destroyer of teeth enamel, as it erodes the enamel some may even results in depth eruption of dentine and results in tooth discolouration. Hence mouthwashes or mouth rinses are used to remove the retained food particles in a short period of time.

The mouth washes are concentrated aqueous anti-bacterial solution that are used against oral microbes to counter oral infection, cleansing, to get rid of bad breath refreshing ,anti-septic .The mouthwash plats an prominent role in the oral hygiene of an individual, it helps to relieve symptoms of inflamed gums gingivitis. And also it reliably used to destruct the pathogenic germs. The mouth washes are used by most of the dental patients to overcome sour mouth (xerostomia), ulcerated throat and sensitive teeth. Dentists always use mouthwash as an antimicrobial agent before oral surgery of the patients, because they help to sterilise the surface of the inflamed gums and teeth, thereby the contamination of any other microorganisms can be avoided.

The Pomegranate (Punica granatum L.) is an ancient fruit. The pomegranate belongs to the family Punicaceae. It is native from the area of Iran to the Himalayas in northern India, and has been cultivated and naturalized over the entire Mediterranean region since ancient times. A clinical analyses determine the leaf mineral contents ( $\mathrm{N}, \mathrm{P}, \mathrm{K}, \mathrm{Ca}, \mathrm{Mg}$ and $\mathrm{Fe}$ ) were significantly affected the organisms with anti-oxidant treatments. The pomegranate extracts shows effective reduction of pathogens in chronic periodontal disorders. The pomegranate are anti-inflamatory in nature, hence they are used to treat against oral-ailments. The pomegranate possess active polyphenolic flavonoids like punicalagins and ellagic acids which helps to prevent gingivitis and or-potential of the mouth.

The Mentha leaves (Mentha longifolia) are aromatic, perennial herbs. The mentha 
belongs to the family Lamiaceae. Peppermint was first described in 1753 by Carl Linnaeus. Mentha are extensively used as flavouring ingredient in breath freshness, antiseptic mouth rinses, chewing gums and tooth paste. The pulegone primarily responsible for the aroma and flavour of spearmint is L-Carvone. Menthol oil contains menthone, menthyl esters, menthyl acetate and menthofuran. Mint also consists of small amounts of many additional compounds including Limonene, Pulegone, Caryophyllene and Pinene.

The use of Neem are known from ancient dates back since 45,000 years against oral diseases. The neem leaves Azadirachta indica belongs to the family Lamiaceae. The neem solutions are used in decreasing the inflammation of gums, to remove canker and against dental cavities. Nowadays the neem extracts are used as antiseptic substance against inflammation of mouth. The neem extract shows significant effects on both Gram positive and Gram negative bacteria such as Staphylococcus spp, Streptococcus spp, E.coli and Salmonella.

A.indicahas inhibition against the production of insoluble glucan, which is the main cause for plaque formation. Theneem sticks has proven to show markedly inhibition against Streptococci, which colonise the surface of the tooth.

The Basil leaves (Ocimumbasilicum L.) is an annual herbs, which is used as an antimicrobial and antifungal substance against oral microbes. The basil leaves are used by Hindus since, dates back for reducing morning bad breathe. It consists of phytochemical compound Terpenes, cineole and other allophatic compounds. It also consists of Linalool and methyl eugenol as essential oil. The basil leaves naturally has
$0.1 \%$ mercuric chloride, thus it helps in the instant whitening of teeth. The basil leaves shows high microbial activity against Streptococcus pyogenes, Staphylococcus aureus and E.coli.

Turmeric (Curcuma longa) a rhizomatous, herbaceous plant of the ginger family zingiberaceae. It is native to south west India requiring temperatures between 20 and $30 \mathrm{C}$ and the plants are gathered anually for their rhizomes. Turmeric was first used as a dye by ancients, then later for its medicinal properties. The important chemical components of turmeric are a group of compounds called curcuminoids that includes demethoxycurcumin and bisdemethoxycurcumin. The other volatile compounds include turmerone, altantone and zingiberine. According to the National centre for complementary and Integrative health, some researches shows compound in turmeric to have antifungal and antibacterial properties.

Chlorhexidine is a chemical antiseptic solution against Gram positive and negative bacteria, aerobic and anaerobic spp. It is used in dental surgery to create germ-free environment, periodontal treatment, halitosis and Xerostomia. It is highly used in the dental disorders patients especially, individuals using permanent braces. Turmeric oil plays a vital role in killing oral cancer cells. Curcumin loaded nanoparticles were used in chemotherapy resistant against oral submucous fibrosis. Turmeric extracts can replace chlorhexidine, as it helps to reduce burning sensation, staining of teeth, allergy-type symptoms, numbness of teeth and destruct plaque forming bacteria.

The aim to prepare Anti-bacterial Herbal Mouthwash from the aqueous extracts of 4 different leaves namely Azadirachta 
indica(Neem), Ocimum basilicum(Tulsi), Mentha longifolia(Mint), Punica granetum Linn (Pomegranate) and rhizomes of Curcuma longa (Turmeric) that acts against the oral pathogens- Staphylococcus aureus, Streptococcus pyogenes, Lactobacillus bulgaricus, Bacillus subtilis and Escherchia coli and to check the Anti-microbial activity by using Agar well diffusion method.

The present study objectives includes that to prepare the aqueous extracts of Azadirachta indica (Neem), Ocimum basilicum Tulsi), Mentha longifolia(Mint), Punica granetum Linn (Pomegranate) and Curcuma longa ( Turmeric ).

To isolate and study the colony morphology of the oral microorganisms-Staphylococcus aureus, Streptococcus pyogenes, Lactobacillus bulgaricus, Bacillus subtilis and Escherichia coli by using culture media and biochemical tests.

To perform the agar well diffusion technique in the Muller Hinton agar and to identify the anti-bacterial activity of leaf extracts against test organisms,by measuring the zone of inhibition.

To compare the efficacy of extracts of 4 different herbal leaves on the basis of their resistancy and sensitivity towards the oral microbes and to formulate the herbal mouthwash.

\section{Materials and Methods}

Test organisms: The isolates of Mouth organisms like Staphylococcus aureus, Streptococcus pyogenes, Lactobacillus bulgaricus, Bacillus subtilis and Escherchia coli, were collected by using sterile oral swab under aseptical condition. They were sub-cultured in peptone water and maintained in refrigerator for longer period of storage.

\section{Collection of organisms}

Oral swab: The sterile absorbent cotton was rolled against the tip of the wooden stick besides the flame to avoid spores and were sterilised by autoclaving at $121^{\circ} \mathrm{C}$ for 15 mins. The swab was rubbed on to the gums and periodontal region of both upper and lower jaws of the individuals. Totally 25 oral swabs were collected from the individuals under sterile condition inside the laboratory.

Peptone water: $1.5 \mathrm{~g}$ of peptone water was weighed and dissolved in $100 \mathrm{ml}$ of distilled water, mixed gently and were autoclaved at $121^{\circ} \mathrm{C}$ for $15 \mathrm{mins}$.Cooled to $50-55^{\circ} \mathrm{C}$ and transferred to sterile test tubes, the oral swabs were inoculated and incubated at $37^{\circ} \mathrm{C}$ for $1 \mathrm{~h}$ and results were observed.

Maintaining the culture: The culture was allowed to store in Refrigerator and frequently subcultured by inoculating it in Nutrient slant or Peptone water for long period of usage.

Collection of Plant Leaves: Leaves of Azadirachtaindica(Neem),

Ocimumteniflorum(Tulsi), Mentha longifolia(Mint), Punicagranetum Linn(Pomegranate) and rhizomes of Curcuma longa (Turmeric) were randomly collected from mature plants.

Extraction process: The leaves were washed with sterile water,shadowdried,pulverized and stored in air-tight bottles. The Aqueous extracts were prepared by soaking the powdered leaves in sterile distilled water and maintained in Incubator at $37^{\circ} \mathrm{C}$ for $72 \mathrm{~h}$ and were filtered using Whattmann filter paper and used for identifying organisms

Equipments: Sterile Petriplates, Testtubes, 
Conicalflask, Whattmann filterpaper, Incubator, Autoclave, Laminar air flow, Pippetting device, Hotair-oven.

Preliminary test for organisms: The collected samples were cultivated and the colony morphology on the culture media Nutrient agar were examined. A colony was picked, inoculated in peptone water and incubated at $37^{\circ} \mathrm{C}$ for $1 \mathrm{~h}$. The isolates were streaked on specific medium- Blood agar, Macconkey agar, Manitol salt agar, Eosine methylene blue and Lactobacillus Mann rogosa agar. Meanwhile, the isolates were identified with Gram staining techniques, Motility test and biochemical tests.

\section{Antibacterial activity of Herbal leaves}

The antibacterial activity of Aqueous extracts of Azadirachtaindica, Ocimumbasilicum, Mentha longifolia, Punicagranetum Linn and rhizomes of Curcuma longa was determined against the test organism-Lactobacillus bulgaricus, Staphylococcus aureus, Streptococcus pyogenes, Bacillus subtilis ,Eschrechia coli by agar well diffusion method.

\section{Aqueous extracts of Leaves by Shadow drying technique}

(i) The leaves of mature plants were collected and washed 3-5 times with tap water to remove dust and dirt.

(ii) The leaves were allowed to soak in already boiled water bath at $30-40^{\circ} \mathrm{C}$ for 10 15 mins to kill microbes present in the surface of the leaves.

(iii) The leaves undergoes Shadow drying technique were the leaves were spread in sterile container trays and kept at ambient temperature for 5 days. (iv) After 5 days, the dried leaves were taken and powdered by using sterile mixer under aseptic condition.

(v) The pulverized leaves are transferred to air-tight sterile container jars.

(vi) $100 \mathrm{ml}$ of sterile distilled water was taken in 4 conical flask $(250 \mathrm{ml})$, the pulverised leaves were weighed and suspended in distilled water under sterile condition.

(vii) The preparation was heat sterilised at $40^{\circ} \mathrm{C}$ for $5-10$ mins and was kept for incubation at $37^{\circ} \mathrm{C}$ for $72 \mathrm{~h}$.

(viii) After incubation, the extracts were filtered with the help of a sterile Whattmann filter paper no: 1 and a funnel under lab condition.

(ix)The filtered extracts are boiled vigorously again to kill the bacterial spores, which will prevent from contamination.

(x) The extracts after heating is ready to use for the formulation of Mouth wash and also can be tested against the oral pathogens by using Agar well diffusion techniques.

\section{Collection of organisms}

(i) 25 students were selected randomly for the collection of mouth organisms.

(ii) The oral swabs were rubbed on the periodontal region of their mouth gently, under aseptic condition.

(iii) The collected swabs were inoculated in freshly prepared saline or peptone water and incubated at $37^{\circ} \mathrm{C}$ for $2 \mathrm{~h}$. 
(iv) The luxuriantly grown organisms were isolated and identified in culture media or by using biochemical techniques.

(v) After using the culture, it was refrigerated till the next use, meanwhile before using the culture, they were incubated at $37^{\circ} \mathrm{C}$ for $2 \mathrm{~h}$.

\section{Isolation of Organisms}

(i) 25 plates of nutrient agar was prepared by above mentioned procedure, each plates were inoculated with 25 swabbed culture by using Streak plate technique and was incubated at $37^{\circ} \mathrm{C}$ for 24 h.

(ii) After incubation, the 2-3 different colonies were observed in the plates, 5 randomly selected colonies were picked out and transferred to the freshly prepared saline and incubated at $37^{\circ} \mathrm{C}$ for $2 \mathrm{~h}$.

(iii) The isolates after incubation was identified by preliminary test such as Gram staining technique, Motility test, Catalase and Oxidase test.

(iv)The isolates were streaked on the specific agar plates such as Blood agar, Macconkey agar, Emb agar and Lactobacillus MRS agar and also inoculated into biochemical tubes under sterile condition which was then, incubated at $37^{\circ} \mathrm{C}$ for $24 \mathrm{~h}$.

(v) After incubation at $37^{\circ} \mathrm{C}$ for $24 \mathrm{~h}$, the plates were observed for colony morphology and the isolates were differentiated by identifying the biochemicals.

\section{Agar well diffusion technique}

(i) A sterile conical flask was taken and filled with $500 \mathrm{ml}$ of distilled water. (ii) $19.0 \mathrm{~g}$ of agar was weighed and dissolved in the water and a pinch of agaragar was added for solidifying the media.

(iii) The media was autoclaved at $121^{\circ} \mathrm{C}$ for 15 mins, cool to $55^{\circ} \mathrm{C}$.

(iv) $5-7 \mathrm{ml}$ of agar was poured in the 25 petriplates, to form a thick agar plate and kept in room temperature to get settled.

(v) The plates were then air dried and UV radiated in the laminar air flow for 5-10 mins.

(vi) The agar wells were punctured by using sterile micropipette tips with equal intervals and the dilutions were marked as $50 \mu 1,100 \mu 1,150 \mu 1$ for each extracts.

(vii) The isolated bacterial colonies were picked from the test organism culture media and inoculated in peptone water or saline and was incubated at $37^{\circ} \mathrm{C}$ for $2 \mathrm{~h}$.

(viii)After incubation the bacterial cultures were compared with 0.5 Mac Farland's standard, for the standardization of the bacterial cultures.

(ix) With the help of oral swab the isolates were swabbed on the upper surface of the agar gently, under sterile condition.

(x)The micro pipette is used to transfer the aqueous extracts in each wells and incubated at $37^{\circ} \mathrm{C}$ for $24 \mathrm{~h}$.

(xi) After 24h, the plates shows agar diffusion around the wells and the results were identified by measuring the zone of inhibition.

(xii) The zone of inhibition was identified for the resistance of the organisms. 


\section{Results and Discussion}

\section{Aqueous extraction of herbal leaves}

The aqueous extracts of the leaves were done by suspending shadow dried and pulverized leaf powder in sterile distilled water. The leaf extracts were subjected to heat, vigorously to kill all the aerobes and spores, there by the extracts are free from contaminants. On the other hand, the component of leaf and its antigenicity were not lost by heating. The aqueous extract is purely herbal hence no chemical component is involved in the preparation of the extracts. The aqueous extracts were prepared as it shows very less side-effects than the other commercially available chemical mouth washes. The herbal mouth washes are homemade hence it is of low expenditure whereas, the commercially available mouthwash is cost-effective. The herbal mouthwash has short shelf life when compared to chemical mouthwash but the storage of unsealed mouthwash may tend to invade the air microbes and other facultative anaerobes.

The extracts of Neem is taken very less amount due to its bitterness, it acts as Anti inflammatory component against bleeding gums. Mint is known for its aroma hence it helps to get rid of bad breath. Pomegranate leaves possess flavonoids which is used as an antioxidant in conditions of Xerostomia. Tulsi extracts were used as they consists of little amount of mercury chloride as a leaf component, which acts as natural whitener. It helps in destruction of oral microbes by preventing oral disorders like pyorrhea and cavities. Turmeric is used to replace chlorhexidine, it is an anti-microbial and anti-septic agent used in oral hygiene.

\section{Isolation of test organisms}

The isolates from the collected oral swabs were identified with the help of culture media and biochemical techniques. The test organisms were isolated and identified and the results were recorded based on the morphological and cultural characters.

\section{Anti-bacterial activity}

The Herbal mouthwash prepared by the aqueous extract from the leaves of the herbs shows:

The Herbal mouth wash was prepared from 4 different leaves- Neem (Azadirachta indica), Pomegranate (Punica granetum Linn), Basil (Ocimum baslicum) and Mint (Mentha longifolia) by Aqueous extraction method, thus the mouthwash was purely, herbal and contains no chemical ingredient. And also the leaves were allowed to shadow dried hence the phytochemical component and the antibacterial activity of the leaves are not lost.

The isolates of the oral test organismsStaphylococcus aureus, Streptococcus pyogenes, Lactobacillus bulgaricus, Bacillus subtilis and Escherchia coli were idententified and isolated by using Streak plate method in culture media like Nutrient agar, Blood agar, Macconkey agar, Eosine methylene blue agar and Lactobacillus MRS agar.

The extracts were taken in different dilutions and inoculated against the swabbed test isolates in Mueller Hinton agar and the sensitivity and resistance of the test organism against the formulated mouth wash were analysed. As by their effectiveness the dilution of the extracts were formulated.

Punica granetum Linn (Pomegranate) shows sensitivity towards the Streptococcus pyogenes, Lactobacillus bulgaricus, Staphylococcus aureus, Bacillus subtilis and Escherchia coli. Hence this study 
proves that Punica granetum Linn (Pomegranate) shows effectiveness against all the 5 oral bacterias namely Streptococcus pyogenes, Lactobacillus bulgaricus, Staphylococcus aureus, Bacillus subtilis and Escherchia coli (Table.1-5 and Figure.1-6).

Table.1 Zone of inhibition in Neem Extracts

\begin{tabular}{|l|l|c|c|c|c|}
\hline S.no & ORAL MICROBES & $\begin{array}{c}\text { DILUTION } \\
\text { OF THE } \\
\text { EXTRACTS }\end{array}$ & $\begin{array}{c}\text { ZONE OF } \\
\text { INHIBITION }\end{array}$ & SENSITIVITY & RESISTANCE \\
\hline 1 & Staphylococcus & $50 \mu \mathrm{l}$ & $7 \mathrm{~mm}$ & + & - \\
\hline & & $100 \mu \mathrm{l}$ & $10 \mathrm{~mm}$ & + & - \\
\hline 2 & S. pyogenes & $150 \mu \mathrm{l}$ & $15 \mathrm{~mm}$ & + & - \\
\hline & & $50 \mu 1$ & $18 \mathrm{~mm}$ & - & + \\
\hline 3 & Escherchia coli & $100 \mu \mathrm{l}$ & $22 \mathrm{~mm}$ & - & + \\
\hline & & $150 \mu \mathrm{l}$ & $24 \mathrm{~mm}$ & - & + \\
\hline 4 & L. bulgaricus & $50 \mu \mathrm{l}$ & $17 \mathrm{~mm}$ & + & - \\
\hline & & $100 \mu \mathrm{l}$ & $21 \mathrm{~mm}$ & + & - \\
\hline & & $150 \mu \mathrm{l}$ & $25 \mathrm{~mm}$ & + & + \\
\hline 5 & Bacillus subitilis & $50 \mu \mathrm{l}$ & $9 \mathrm{~mm}$ & - & + \\
\hline & & $100 \mu \mathrm{l}$ & $10 \mathrm{~mm}$ & - & + \\
\hline & & $150 \mu \mathrm{l}$ & $12 \mathrm{~mm}$ & - & + \\
\hline
\end{tabular}

Table.2 Zone of inhibition in Tulsi Extracts

\begin{tabular}{|l|l|c|c|c|c|}
\hline S.no & ORAL MICROBES & $\begin{array}{c}\text { DILUTION } \\
\text { OF THE EXTRACTS }\end{array}$ & $\begin{array}{c}\text { ZONE OF } \\
\text { INHIBITION }\end{array}$ & SENSITIVITY & RESISTANCE \\
\hline 1 & Staphylococcus aureus & $50 \mu \mathrm{l}$ & $18 \mathrm{~mm}$ & + & - \\
\hline & & $100 \mu \mathrm{l}$ & $20 \mathrm{~mm}$ & + & - \\
\hline & & $150 \mu 1$ & $23 \mathrm{~mm}$ & + & - \\
\hline 2 & Streptococcus pyogenes & $50 \mu 1$ & $10 \mathrm{~mm}$ & - & + \\
\hline & & $100 \mu 1$ & $14 \mathrm{~mm}$ & - & + \\
\hline & & $150 \mu 1$ & $19 \mathrm{~mm}$ & - & + \\
\hline 3 & Escherchia coli & $50 \mu 1$ & $15 \mathrm{~mm}$ & + & - \\
\hline & & $100 \mu 1$ & $19 \mathrm{~mm}$ & + & - \\
\hline & & $150 \mu 1$ & $25 \mathrm{~mm}$ & + & - \\
\hline 4 & L.bulgaricus & $50 \mu 1$ & $11 \mathrm{~mm}$ & - & + \\
\hline & & $100 \mu 1$ & $13 \mathrm{~mm}$ & - & + \\
\hline & & $150 \mu 1$ & $16 \mathrm{~mm}$ & - & + \\
\hline 5 & Bacillus subitilis & $50 \mu 1$ & $10 \mathrm{~mm}$ & + & - \\
\hline & & $100 \mu 1$ & $12 \mathrm{~mm}$ & + & - \\
\hline & & $150 \mu 1$ & $18 \mathrm{~mm}$ & + & - \\
\hline
\end{tabular}


Int.J.Curr.Microbiol.App.Sci (2016) 5(11): 205-221

Table.3 Zone of inhibition in Mint Extracts

\begin{tabular}{|c|c|c|c|c|c|}
\hline S.no & ORAL MICROBES & $\begin{array}{l}\text { DILUTION } \\
\text { OF THE } \\
\text { EXTRACTS }\end{array}$ & $\begin{array}{l}\text { ZONE OF } \\
\text { INHIBITION }\end{array}$ & SENSITIVITY & RESISTANCE \\
\hline \multirow[t]{3}{*}{1} & Staphylococcus aureus & $50 \mu 1$ & $16 \mathrm{~mm}$ & + & - \\
\hline & & $100 \mu \mathrm{l}$ & $17 \mathrm{~mm}$ & + & - \\
\hline & & $150 \mu \mathrm{l}$ & $22 \mathrm{~mm}$ & + & - \\
\hline \multirow[t]{3}{*}{2} & Streptococcus pyogenes & $50 \mu \mathrm{l}$ & $9 \mathrm{~mm}$ & - & + \\
\hline & & $100 \mu \mathrm{l}$ & $10 \mathrm{~mm}$ & - & + \\
\hline & & $150 \mu \mathrm{l}$ & $12 \mathrm{~mm}$ & - & + \\
\hline \multirow[t]{3}{*}{3} & Escherchia coli & $50 \mu \mathrm{l}$ & $15 \mathrm{~mm}$ & + & - \\
\hline & & $100 \mu \mathrm{l}$ & $18 \mathrm{~mm}$ & + & - \\
\hline & & $150 \mu \mathrm{l}$ & $20 \mathrm{~mm}$ & + & - \\
\hline \multirow[t]{3}{*}{4} & L.bulgaricus & $50 \mu \mathrm{l}$ & $9 \mathrm{~mm}$ & + & - \\
\hline & & $100 \mu \mathrm{l}$ & $11 \mathrm{~mm}$ & + & - \\
\hline & & $150 \mu \mathrm{l}$ & $17 \mathrm{~mm}$ & + & - \\
\hline \multirow[t]{3}{*}{5} & Bacillus subitilis & $50 \mu 1$ & $9 \mathrm{~mm}$ & - & + \\
\hline & & $100 \mu \mathrm{l}$ & $10 \mathrm{~mm}$ & - & + \\
\hline & & $150 \mu \mathrm{l}$ & $12 \mathrm{~mm}$ & - & + \\
\hline
\end{tabular}

Table.4 Zone of inhibition in Pomegranate Extracts

\begin{tabular}{|l|l|l|l|l|l|}
\hline S.no & ORAL MICROBES & $\begin{array}{l}\text { DILUTION } \\
\text { OF THE } \\
\text { EXTRACTS }\end{array}$ & $\begin{array}{l}\text { ZONE OF } \\
\text { INHIBITION }\end{array}$ & SENSITIVITY & RESISTANCE \\
\hline 1 & Staphylococcus aureus & $50 \mu \mathrm{l}$ & $23 \mathrm{~mm}$ & + & - \\
\hline & & $100 \mu \mathrm{l}$ & $26 \mathrm{~mm}$ & + & - \\
\hline & & $150 \mu \mathrm{l}$ & $33 \mathrm{~mm}$ & + & - \\
\hline 2 & Streptococcus pyogenes & $50 \mu \mathrm{l}$ & $21 \mathrm{~mm}$ & + & - \\
\hline & & $100 \mu \mathrm{l}$ & $23 \mathrm{~mm}$ & + & - \\
\hline & & $150 \mu \mathrm{l}$ & $25 \mathrm{~mm}$ & + & - \\
\hline 3 & Escherchia coli & $50 \mu \mathrm{l}$ & $20 \mathrm{~mm}$ & + & - \\
\hline & & $100 \mu \mathrm{l}$ & $24 \mathrm{~mm}$ & + & - \\
\hline & & $150 \mu \mathrm{l}$ & $25 \mathrm{~mm}$ & + & - \\
\hline 4 & L.bulgaricus & $50 \mu \mathrm{l}$ & $22 \mathrm{~mm}$ & + & - \\
\hline & & $100 \mu \mathrm{l}$ & $24 \mathrm{~mm}$ & + & - \\
\hline & & $150 \mu \mathrm{l}$ & $31 \mathrm{~mm}$ & + & - \\
\hline 5 & Bacillus subitilis & $50 \mu \mathrm{l}$ & $20 \mathrm{~mm}$ & + & - \\
\hline & & $100 \mu \mathrm{l}$ & $21 \mathrm{~mm}$ & + & - \\
\hline & & $150 \mu \mathrm{l}$ & $23 \mathrm{~mm}$ & + & - \\
\hline
\end{tabular}


Table.5 Zone of inhibition in formulated Herbal Mouthwash

\begin{tabular}{|l|l|l|l|l|l|}
\hline S.no & ORAL MICROBES & $\begin{array}{l}\text { DILUTION } \\
\text { OF THE } \\
\text { EXTRACTS }\end{array}$ & $\begin{array}{l}\text { ZONE OF } \\
\text { INHIBITION }\end{array}$ & SENSITIVITY & RESISTANCE \\
\hline 1 & Staphylococcus aureus & $50 \mu \mathrm{l}$ & $11 \mathrm{~mm}$ & - & + \\
\hline & & $100 \mu \mathrm{l}$ & $10 \mathrm{~mm}$ & - & + \\
\hline & & $150 \mu \mathrm{l}$ & $16 \mathrm{~mm}$ & - & + \\
\hline 2 & S. pyogenes & $50 \mu \mathrm{l}$ & $11 \mathrm{~mm}$ & - & + \\
\hline & & $100 \mu \mathrm{l}$ & $12 \mathrm{~mm}$ & - & + \\
\hline & & $150 \mu \mathrm{l}$ & $15 \mathrm{~mm}$ & - & + \\
\hline 3 & Escherchia coli & $50 \mu \mathrm{l}$ & $11 \mathrm{~mm}$ & - & + \\
\hline & & $100 \mu \mathrm{l}$ & $14 \mathrm{~mm}$ & - & + \\
\hline & & $150 \mu \mathrm{l}$ & $15 \mathrm{~mm}$ & - & + \\
\hline 4 & L.bulgaricus & $50 \mu \mathrm{l}$ & $9 \mathrm{~mm}$ & - & + \\
\hline & & $100 \mu \mathrm{l}$ & $15 \mathrm{~mm}$ & - & + \\
\hline & & $150 \mu \mathrm{l}$ & $16 \mathrm{~mm}$ & - & + \\
\hline 5 & Bacillus subitilis & $50 \mu \mathrm{l}$ & $8 \mathrm{~mm}$ & + & - \\
\hline & & $100 \mu \mathrm{l}$ & $11 \mathrm{~mm}$ & + & - \\
\hline & & $150 \mu \mathrm{l}$ & $13 \mathrm{~mm}$ & + & - \\
\hline
\end{tabular}

Fig.1 Antimicrobial activity of Pomegranate extracts.
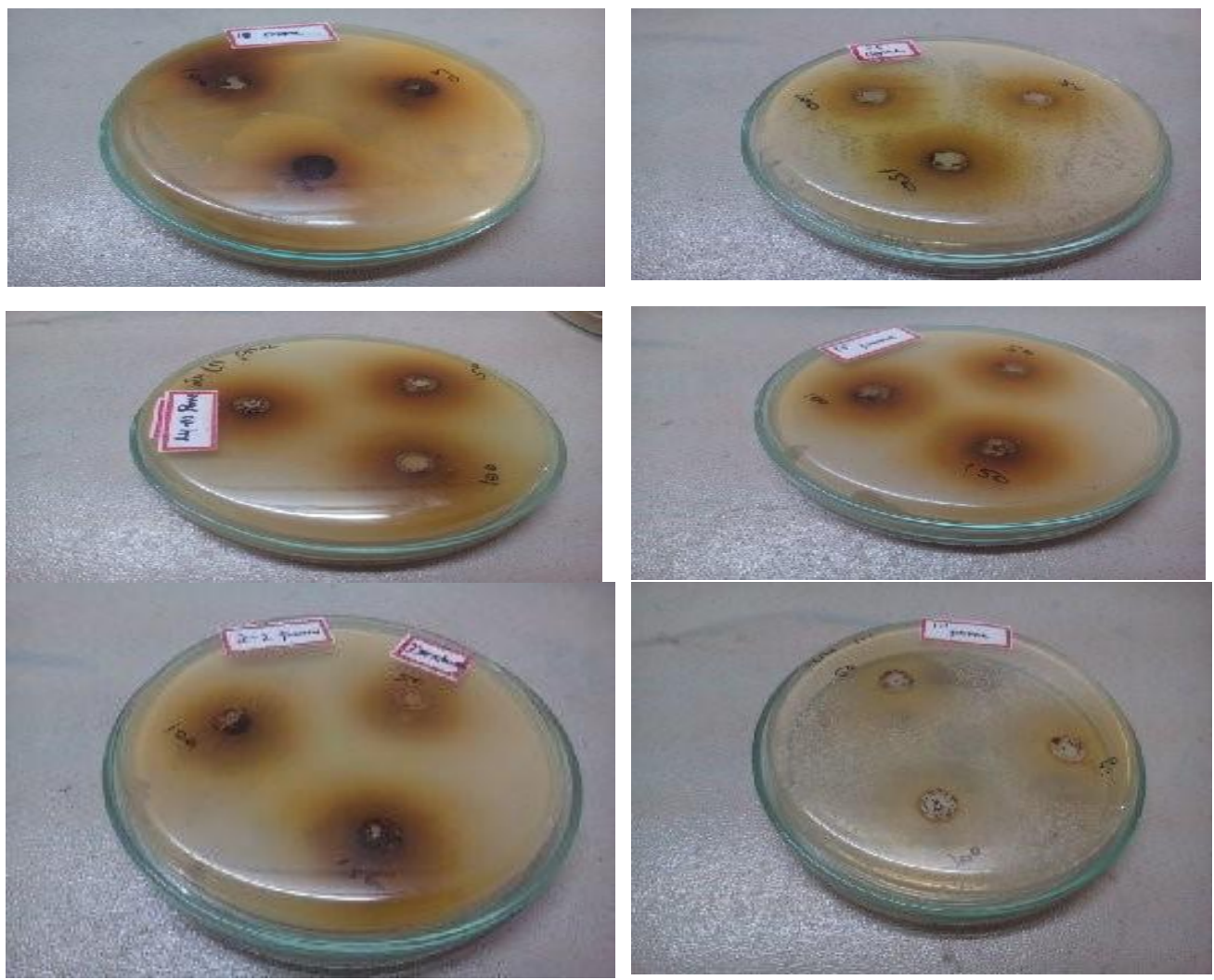
Int.J.Curr.Microbiol.App.Sci (2016) 5(11): 205-221

Fig.2 Antimicrobial activity of Mint extracts.
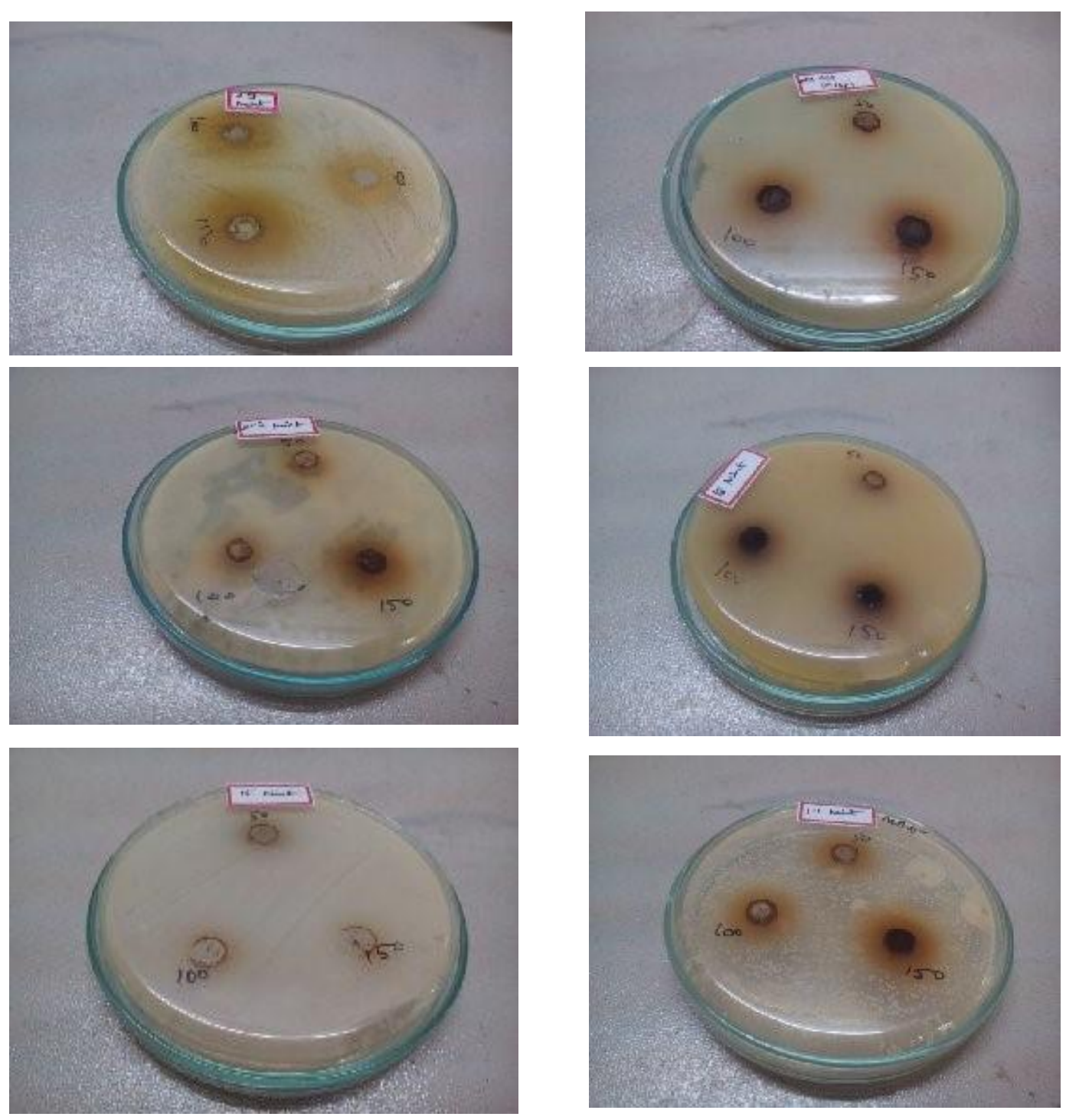
Fig.3 Antimicrobial activity of Neem extracts.
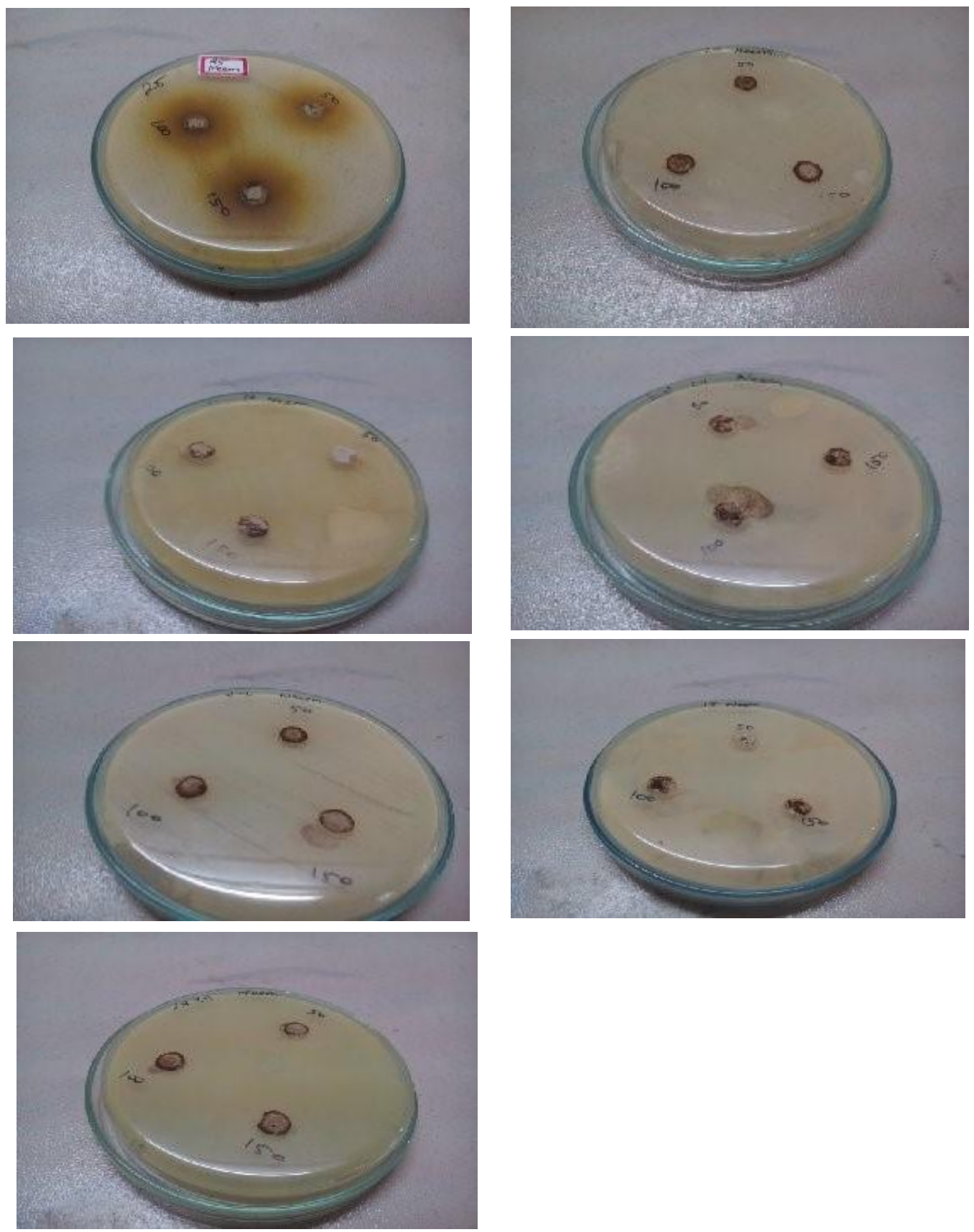
Int.J.Curr.Microbiol.App.Sci (2016) 5(11): 205-221

Fig.4 Antimicrobial activity of Tulsi extracts
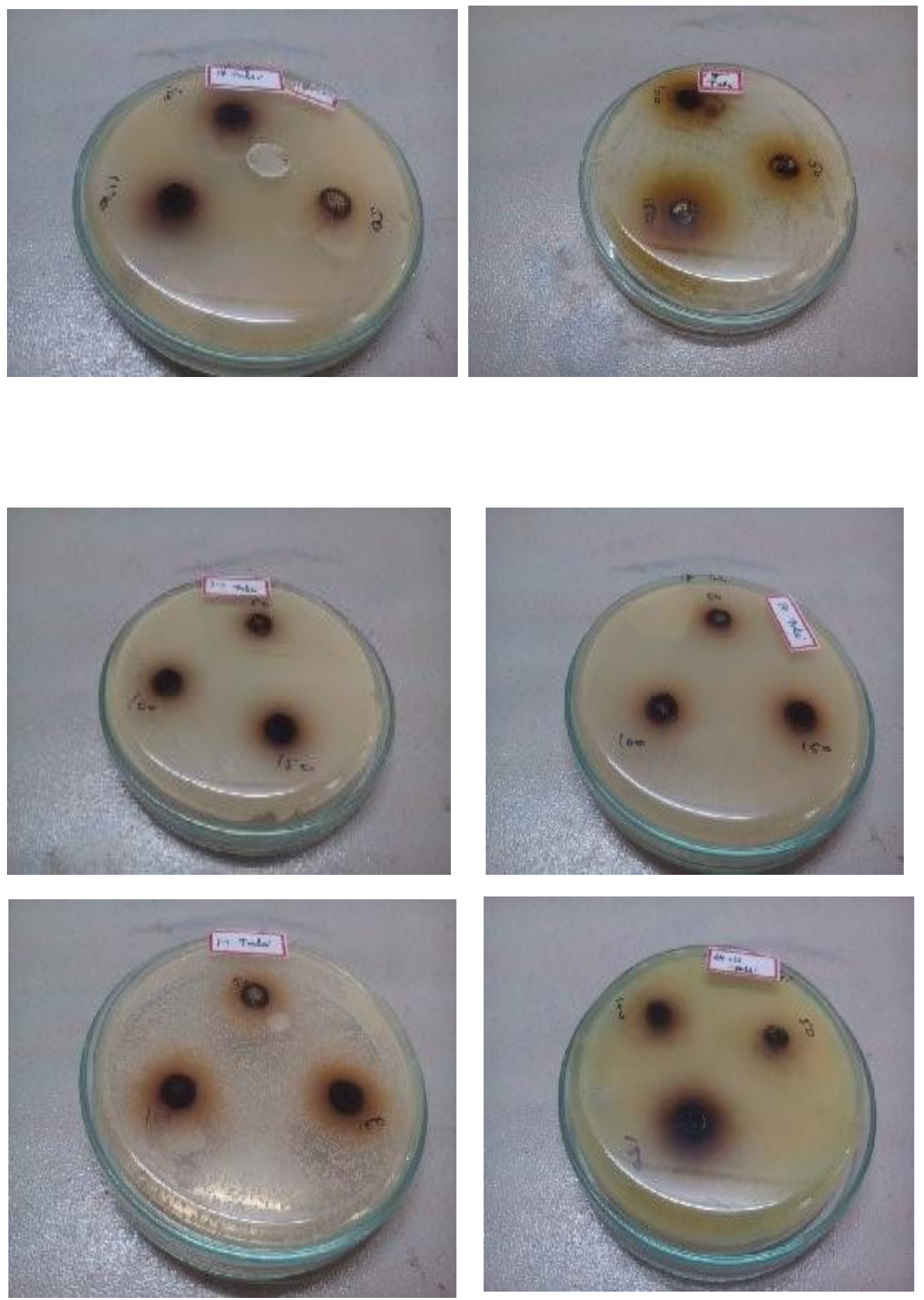
Fig.5 Antimicrobial activity of Turmeric

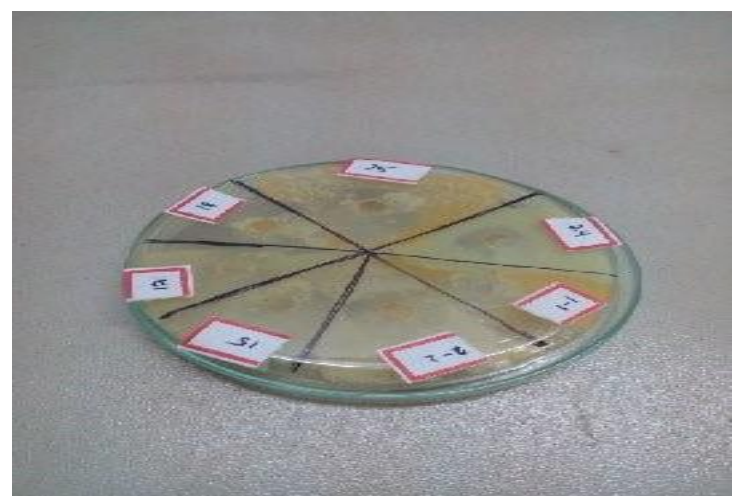

Fig.6 Antimicrobial activity of Formulated Herbal Mouthwash.
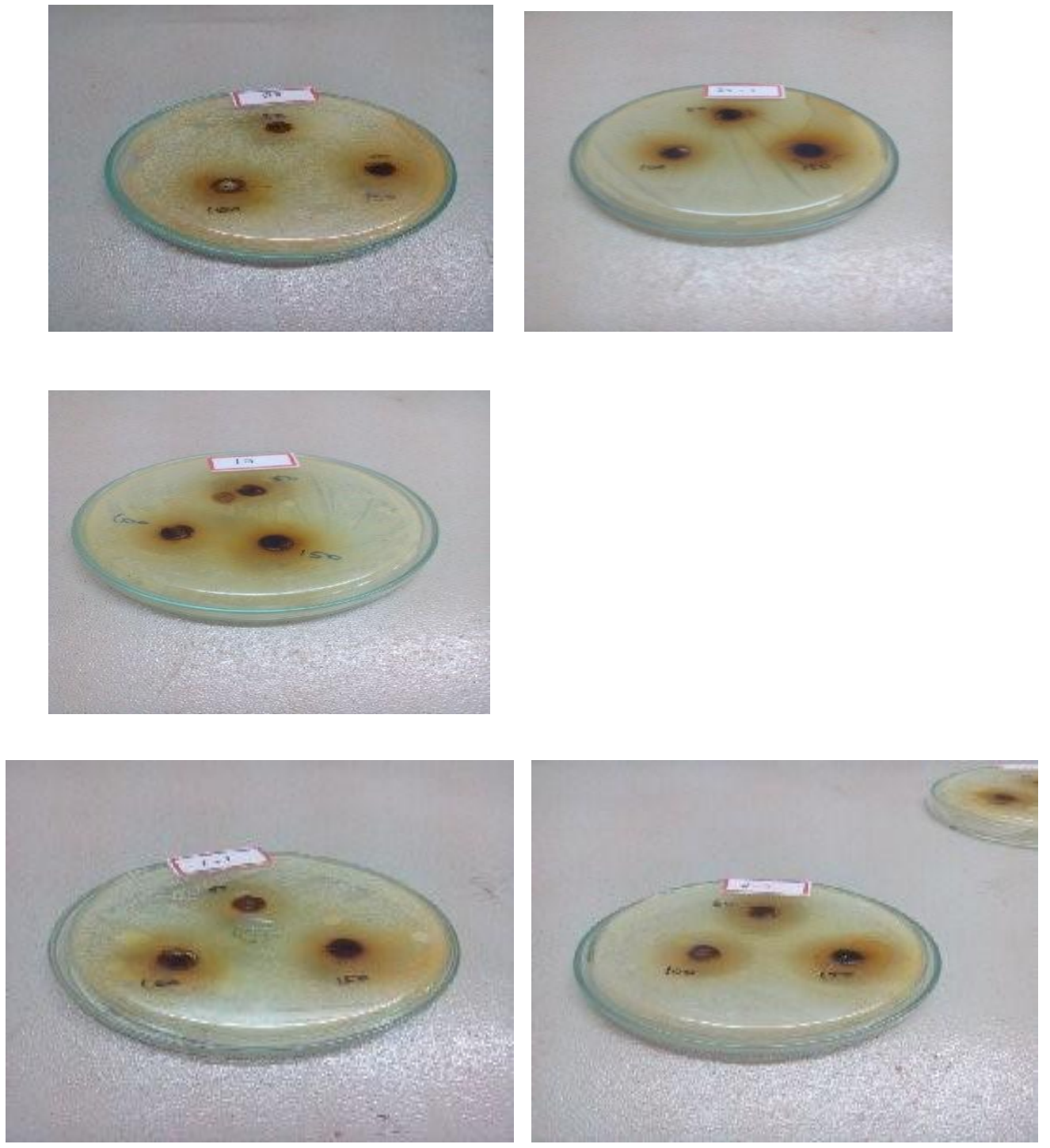
Int.J.Curr.Microbiol.App.Sci (2016) 5(11): 205-221

(i) Punica granetum Linn (Pomegranate) shows sensitivity towards the Streptococcus pyogenes, Lactobacillus bulgaricus, Staphylococcus aureus, Bacillus subtilis and Escherichia coli. From the study it was found to show sensitivity to Streptococcus pyogenes, alike the research on Herbal mouthwashes- A Gift of nature by Dr.Bhavnajhakukreja et al.,2012. Hence this study proves that Punica granetum Linn(Pomegranate) shows effectiveness against all the 5 oral bacterias namely Streptococcus pyogenes, Lactobacillus spp, Staphylococcus aureus, Bacillus subtilis and Escherchia coli. Thereby, Pomegranate leaves can also be included in the preparation of Herbal mouthwashes.Eventually, from the study of Screening of Aqueous extracts of medicinal herbs for antimicrobial activity against oral bacteria by NamHuiYim et al., 2013 has showed sensitivity to all oral pathogens.

(ii)Azadirachta indica (Neem) shows sensitivity towards Staphylococcus aureus and Escherchia coli and shows resistance towards Streptococcus pyogenes, Lactobacillus bulgaricus and Bacillus subtilis. But the study, Antimicrobial Efficacy of Herbal and Chlorhexidine Mouth rinse- A systematic review by Dr.N.Nagappan et al., 2012 has concluded that the herbal mouth rinse containing neem extract shows low sensitivity towards Streptococcus sppwhen compared to chlorhexidine mouthwash. Similarly,the study by Yetty Herdiyati et al., 2013 - Differences in the Effectiveness of Herbal, Betel leaves and Chlorhexidine Mouthwash on Plaque Reduction in Orphanage children resulted that, betel leaves has showed, high sensitivity towards plaque forming organism-Streptococcus pyogene sthan Chlorhexidine.

(iii)Ocimum baslicum (Tulsi) shows sensitivity towards Staphylococcus aureus, Bacillus subtilis and Escherichia coli and shows resistance towards Streptococcus pyogenes, Lactobacillus bulgaricus. Same way from the study, Antimicrobial activity of herbal mouthwash- Arowash liquid by Piyush D.Lashkari et al., 2010 shows more sensitivity towards Staphylococcus aureus but very low sensitivity towards Bacillus subtilis .Meanwhile, the study by Charles O.Esimone -A Case for the Use of Herbal Extracts in Oral Hygiene: The Efficacy of Psidium guajava-Based Mouthwash Formulations, it has showed high sensitivity towards Staphylococcus aureus, Bacillus subtilis and Escherchia coli

(iv)Mentha longifolia (Mint) shows sensitivity towards Staphylococcus aureus, Lactobacillus bulgaricus and Escherchia coli and shows resistance towards Streptococcus pyogenes and Bacillus subtilis. But the study, the antimicrobial effect of aqueous and alcoholic extracts of Eucalyptus leaves on oral Mutansstreptococci, Lactobacilli and Candida albicans (an invitro study),evaluates that the alcoholic extracts of eucalyptus leaves shows sensitivity towards Streptococcus mutans

(v)Curcuma longa (Turmeric) shows sensitivity towards Lactobacillus bulgaricus, Staphylococcus aureus and Escherichia coli and shows resistance towards Streptococcus pyogenes, Bacillus subtilis. From the study it was found to show resistance to Streptococcus pyogenes, whereas the research on Chemical composition and product quality control of Turmeric (Curcuma longa) by Shiyou Li et al., 2011 shows sensitivity to $S$. oralis \& S.mutans

Pomegranate leaves possess flavonoids which is used as an anti-oxidant in conditions of Xerotomia. Thereby, Pomegranate leaves can also be included in the preparation of Herbal mouthwashes.

Azadirachta indica (Neem) shows sensitivity towards Staphylococcus aureus and Escherchia coli. As Neem is known for its bitterness it was include in very small amount in prepared mouthwash and also, it acts as Anti-inflammatory component against bleeding gums
Ocimum baslicum (Tulsi) shows sensitivity towards Staphylococcus aureus, Bacillus subtilis and Escherchia coli. Tulsi extracts were used as they consists of little amount of mercury chloride as a leaf component, which acts as natural whitener. It helps in destruction of oral microbes by preventing oral disorders like pyorrhea and cavities.

Mentha longifolia (Mint) shows sensitivity towards Staphylococcus aureus, L.bulgaricus and Escherchia coli. Mint is known for its aroma hence it helps to get rid of morning-bad breath. It helps to nourishes 
the salivary activity in mouth hence supress the acidic bacteria in oral cavity. Curcuma longa (Turmeric) shows sensitivity towards Lactobacillus bulgaricus, Staphylococcus aureus and Escherchia coli and shows resistance towards Streptococcus pyogenes, Bacillus subtilis. Turmeric is used to replace chlorhexidine, it is an antimicrobial and anti-septic agent used in oral hygiene. Turmeric pack is done in between the time intervals of Oral surgery to supress the growth of oral microbes.

Chlorhexidine is a chemical mouthwash that consists of hydrogen peroxide and mercury chloride, which acts an immediate pain reliever, sterliser of gums and whitener of teeth, but long term use of chlorhexidine may lead to discolouration of teeth by eroding the tooth enamel and they are also cost effective.

The use of herbal mouth rinse is effective as it does not produce any side effect and also economically affordable. The mouth wash consists of purely aqueous extracts hence can be boiled in between once after the bottle is unsealed. On the other hand the prepared mouthwash was effective against all the oral bacteria.

Based on the evidence obtained from this study, Punica granatum L.(Pomegranate) was found to have more effectiveness against almost all the oral bacteria, as it shows sensitivity for all the five tested organisms namely- Staphylococcus aureus, Streptococcus pyogenes, L. bulgaricus, Bacillus subtilis and Escherchia coli. Periodontal diseases leading to gingitivitis, inflammation of gums were caused by the above mentioned microbes.

Thereby, the study suggests to use the Pomegranate extract as one of the ingredient in herbal mouthwash.
Meanwhile, Curcuma longa (Turmeric) shows equal efficacy when compared to chlorhexidine and it is also used in most of the herbal mouthwash as the Standard golden component for the mouthwash. Hence, the work has revealed the use of Curcuma longa (Turmeric) as an ingredient to replace chlorhexidine. Chlorhexidine shows side effects in $\operatorname{IgE}$ hypersensitivity Patients,as it results in Contact dermatitis and also its not advisory for Lactating and Pregnant ladies so Curcuma longa can be used.

The study has concluded that the inclusion of Punicagranatum L.(Pomegranate) in mouth rinse helps in destruction of microbes and also Curcuma longa (Turmeric) replaces Chlorhexidine. Hence the prepared Herbal mouthwash shows effectiveness against oral pathogens like Staphylococcus aureus, Streptococcus pyogenes, Lactobacillus bulgaricus, Bacillus subtilis and Escherchia coli.

\section{References}

Bhavna, J.K., Vidhya, D. 2012. Herbal Mouthwash - A gift of Nature, Int. J. Pharma. and Bio. Sci., Vol 3.

Charles, O.E., Chukwuemeka, S.N., Ubong, S.E., Ifeanyichukwu. R.I., \& Chidimma, S.O. 2007. A Case for the use ofHebal Extracts in oral Hygiene: the efficacy of Psidium guajava- based mouthwash formulations, Res. J. Appl. Sci., 2(11): 1143 - 1147.

Firas, H.Q., Abbas, S.A. 2009. The antimicrobial effect of aqueous \& alcoholic extracts of eucalptus leaves on oral Mutans streptococci, Lactobacilli \& Candida albicans ( an in vitro study), $J$. Bagh. Col. Dent. 21(4).

Harison, M., Jyotsna, K.P., Pratima, T. 2014. A comparative evaluation of antifungal activity of medicinal plant extracts and chemical fungicides against four plant pathogens, Int. J. Curr. Microbiology. 
App. Sci., 3(5): 97 - 109.

Monica, L., Adithya, S.K.D.. Jithendra, Amrinder, S, Ashish, S. 2015. Evaluating the properties of two herbal mouthwashes and their effect on total leukocyte count after phase Itheraphy, Int. Dent. Med. J. Adv. Res., 1: 1 - 5.

Nam - Hui, Y., Young, P. J., Won - Kyung, C., Taesoo, K., Aeyung, K., Minju, I. Jin, Y. M. 2013. Screening of aqueous extracts of medicinal herbs for anti microbial activity against oral bacteria. Integr. Med. Res., 2: 18-24.

Piyush, D.L., Rakesh, K., Patel, Vandhana, M. 2010. Antimicrobial activity ofHerbal Mouth wash-Arowash Liquid, Int. J. Chem. Tech. Res., Vol. 2, No.1, pp : 99 101.

Ritam S.N., Pratima, G., Abhijit N.G., Sujeet V, K.2014. A randomized clinical trail to evaluate and compare the efficacy boftriphala mouthwash with $0.2 \%$ chorhexidine in hosptalized patients with periodontal diseases.copyright, Korean academy of periodontology.

Fayed, T.A. 2010. Effect of Compost Tea and Some Appicants on Leaf Chemical Constituents, Yield and Fruit Quality of Pomegranate, World J. Agri. Sci., 6(4): $402-411$.

Sadik, A., Anes A.M.T., AmeenM. I.A., Naseer,
A., Abdulbaqi A.M.T., \& Zaid, A. 2014. Antimicrobial activity of Yemeni myrrh mouthwash, J. Chem. Pharma., 6(5): 1006 - 1013.

Shiyou, L., Wei, Y., Guangri, D., Ping, Y., and Bharat B. A., 2011. ChemicalComposition and Product Quality Control of Turmeric (Curcuma longa L.). Pharmaceutical Crops, 2, 28 - 54.

Yetty, H., Meirina, G., Ninda, K., Fellani, D, D., 2013. Differences in the Effectiveness of Herbal, Betel Leaves and Chlorhexidine Mouthwash on Plaque Reduction in Orphanage Children, 2013, International Journal of Science and Research (IJSR) Index Copernicus Value : 6 . 14 / Impact Factor: 4: 438.

Zainab, A.A. 2013. Antimicrobial activity of different types of mouthwashes against Streptococcus mutans, Staphylococcus aureusand Candida albicans(In vitro study).Vol. 25 (2), June.

Zohreh, T., Hadi, D.K., Afshin, G.B., Mohammad, A.H.G., Ali, S., and Mohammad, A. 2011. Evaluation of the Antibacterial Effect of Perisca Mouthwash in Mechanically Ventilated Icu Patients: A Double Blind Randomized Clinical Tria. Middle - East J. Scientific Res., 10(5): 631 - 637.

\section{How to cite this article:}

Nasreen Banu, J., and Gayathri, V. 2016. Preparation of Antibacterial Herbal Mouthwash against Oral Pathogens. Int.J.Curr.Microbiol.App.Sci. 5(11): 205-221.

doi: http://dx.doi.org/10.20546/ijcmas.2016.511.023 